\title{
Synapsin Regulates Activity-Dependent Outgrowth of Synaptic Boutons at the Drosophila Neuromuscular Junction
}

\author{
Alexander Vasin, ${ }^{1}$ Lidia Zueva, ${ }^{1}$ Carol Torrez, ${ }^{1}$ Dina Volfson, ${ }^{2}$ J. Troy Littleton, ${ }^{2}$ and Maria Bykhovskaia ${ }^{1}$ \\ ${ }^{1}$ Neuroscience Department, Universidad Central del Caribe, Bayamon, Puerto Rico 00960-6032, and ${ }^{2}$ The Picower Institute of Learning and Memory, \\ Department of Biology, Massachusetts Institute of Technology, Cambridge, Massachusetts 02139-4307
}

\begin{abstract}
Patterned depolarization of Drosophila motor neurons can rapidly induce the outgrowth of new synaptic boutons at the larval neuromuscular junction (NMJ), providing a model system to investigate mechanisms underlying acute structural plasticity. Correlative light and electron microscopy analysis revealed that new boutons typically form near the edge of postsynaptic reticulums of presynaptic boutons. Unlike mature boutons, new varicosities have synaptic vesicles which are distributed uniformly throughout the bouton and undeveloped postsynaptic specializations. To characterize the presynaptic mechanisms mediating new synaptic growth induced by patterned activity, we investigated the formation of new boutons in NMJs lacking synapsin [Syn (-)], a synaptic protein important for vesicle clustering, neurodevelopment, and plasticity. We found that budding of new boutons at Syn(-) NMJs was significantly diminished, and that new boutons in Syn $(-)$ preparations were smaller and had reduced synaptic vesicle density. Since synapsin is a target of protein kinase A (PKA), we assayed whether activity-dependent synaptic growth is regulated via a cAMP/PKA/synapsin pathway. We pretreated preparations with forskolin to raise cAMP levels and found this manipulation significantly enhanced activity-dependent synaptic growth in control but not Syn $(-)$ preparations. To examine the trafficking of synapsin during synaptic growth, we generated transgenic animals expressing fluorescently tagged synapsin. Fluorescence recovery after photobleaching analysis revealed that patterned depolarization promoted synapsin movement between boutons. During new synaptic bouton formation, synapsin redistributed upon stimulation toward the sites of varicosity outgrowth. These findings support a model whereby synapsin accumulates at sites of synaptic growth and facilitates budding of new boutons via a cAMP/PKA-dependent pathway.
\end{abstract}

Key words: active zone; electron microscopy; forskolin; FRAP; synaptic vesicle; synaptotagmin

\section{Introduction}

Neuronal networks modify their activity in response to stimulation, and short-term changes in synaptic efficacy can lead to morphological changes in synaptic ultrastructure. Although postsynaptic structural modifications have been extensively studied (for review, see Holtmaat and Svoboda, 2009), the mechanisms of formation and differentiation of presynaptic boutons remain obscure. The Drosophila neuromuscular junction (NMJ) represents an excellent model system to study presynaptic restructuring because it has distinct and easily quantifiable presynaptic boutons and is amendable to genetic manipulations. Prior studies from the Budnik laboratory (Ataman et al., 2008) used live imaging at intact Drosophila larval NMJs and demonstrated that budding and outgrowth of new presynaptic boutons can occur rapidly in response to patterned depolarization. Although

\section{Received Dec. 4, 2013; revised June 13, 2014; accepted June 17, 2014.}

Author contributions: M.B. and J.T.L. designed research; A.V., L.Z., C.T., and D.V. performed research; D.V. contributed unpublished reagents/analytic tools; M.B., A.V., and C.T. analyzed data; M.B., A.V., and J.T.L. wrote the paper.

This study was supported by the National Institutes of Health Grants U54 NS083924 to M.B. and R01 MH099557 to M.B. and J.T.L.

The authors declare no competing financial interests.

Correspondence should be addressed to Maria Bykhovskaia, Neuroscience Department, Universidad Central del Caribe, 2 U6 Ave Laurel, Lomas Verdes, Bayamon, Puerto Rico 00956. E-mail: mb.ucdelcaribe@gmail.com.

DOI:10.1523/JNEUROSCI.5074-13.2014

Copyright $\odot 2014$ the authors $\quad 0270-6474 / 14 / 3310554-10 \$ 15.00 / 0$ molecular signaling pathways leading to the activity-dependent synaptic outgrowth have been investigated (Ataman et al., 2008; Korkut et al., 2009, 2013; Koon et al., 2011), it remains unknown how new synaptic boutons differentiate and mature and what presynaptic mechanisms mediate their growth. To begin elucidating these mechanisms, we combined optical and electron microscopy (EM) approaches to examine the ultrastructure of newly formed boutons. Furthermore, we investigated the role of the presynaptic protein synapsin in activity-dependent synaptic growth.

Synapsin is the most abundant synaptic phosphoprotein that reversibly attaches to synaptic vesicles and regulates synaptic vesicle clustering and plasticity (for review, see Greengard et al., 1993; Hilfiker et al., 1999; Bykhovskaia, 2011). Importantly, synapsin has been shown to regulate neuronal development, as elevated levels of synapsin accelerate the maturation of presynaptic terminals at frog NMJs (Schaeffer et al., 1994; Valtorta et al., 1995). In addition, neuronal cultures lacking the mouse synapsin II isoform have delayed synapse formation (Ferreira et al., 1998). These studies suggest an important role of synapsin in neuronal development and synapse formation, which may be conserved in invertebrates and vertebrates (for review, see Fornasiero et al., 2010).

Synapsin is a target for protein kinase A (PKA), and PKA phosphorylation sites in synapsin are conserved from inverte- 
A

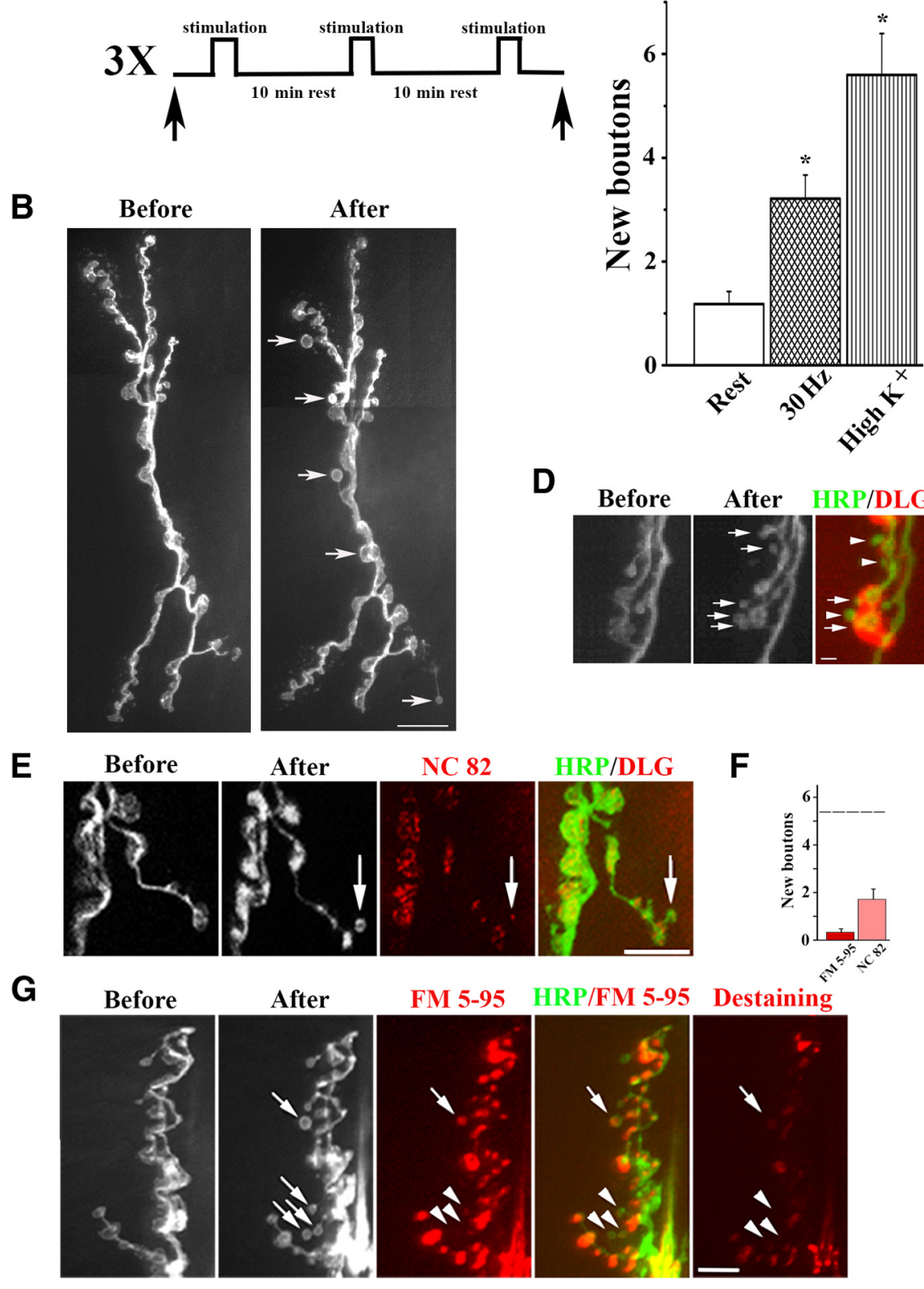

Figure 1. Synaptic outgrowth induced by patterned stimulation. $\boldsymbol{A}$, Stimulation protocol: three spaced stimulations are applied to dissected third instar larvae where axons have been severed from the motor neuron cell body. Either high- $\mathrm{K}^{+}$application (90 $\mathrm{mm} \mathrm{KCl}$ for $2 \mathrm{~min}$ ) or electrical stimulation of the nerve $(30 \mathrm{~Hz}$ for $5 \mathrm{~min}$ ) was used. B. New boutons (arrows) formed upon stimulation. Stacks of confocal images (extended view) of CD8-GFP at NMJ arbors before and after stimulation. C, Both stimulation paradigms (high $\mathrm{K}^{+}$or $30 \mathrm{~Hz}$ frequency) produce a significant growth, although it is more prominent with high- $\mathrm{K}^{+}$stimulation. A very modest growth ( $\sim 1$ bouton per segment, white bar) was also observed at resting conditions ( $30 \mathrm{~min}) . p<0.0001$ per one-way ANOVA; rest: $n=28 ; 30 \mathrm{~Hz}: n=28 ;$ high $\mathrm{K}^{+}: n=42$. D, New boutons are typically formed either at the edge or outside of the SSR. Images of CD8-GFP before and after the stimulation (top and middle) and double immunolabeling of the same preparation for HRP and DLG (bottom). E, Double labeling of stimulated preparations for HRP and NC82 shows NC82 labeling within a new bouton (arrow), indicating that BRP is present. $\boldsymbol{F}$, Only a minority of new boutons contain BRP (NC82 labeling), and $<1$ new bouton per segment shows FM 5-95 loading. The dotted line indicates the overall number of new boutons with this stimulation paradigm. Data collected from eight larvae. G, FM 5-95 loading of stimulated preparations shows that new boutons do not normally recycle vesicles (arrowheads, no FM 5-95 labeling), but occasionally FM 5-95 labeling of new boutons was observed (arrow). Subsequent stimulation in the absence of FM 5-95 (right) produces destaining of the entire preparation, including the new bouton (arrow).

brates to vertebrates (Kao et al., 1999). Synapsin phosphorylation by PKA promotes neurite outgrowth in Xenopus laevis embryos (Kao et al., 2002) and synapse formation in hippocampal cultured neurons (Perlini et al., 2011). Here, we examined the role of synapsin in activity-dependent synaptic growth at Drosophila NMJs, and identified an important function of synapsin in promoting vesicle clustering and transport into new synaptic varicosities.

\section{Materials and Methods}

Drosophila genetics. Flies were cultured on standard medium at $25^{\circ} \mathrm{C}$. Flies of both sexes were used for all experiments. The elav-Gal4 promoter (Bloomington Stock Center) was used to drive upstream activation sequence (UAS)-CD8-GFP (Bloomington Stock Center) expression throughout the nervous system. The synapsin-null mutant (cantonized Syn ${ }^{97}$ ) was a generous gift from Dr. Erich Buchner. The GFP-tagged and RFP-tagged synapsin lines (Syn-eGFP and Syn-mRFP) were produced as follows. The "runt domain" isoform of synapsin (Klagges et al., 1996) was obtained from the Drosophila Genomics Resource Center (DGRC) gene collection (RE44971, stock no. 9229). The synapsin open reading frame was subcloned into pPGW and pPRW vectors downstream of a GAL4-bound UAS cassette by standard Gateway procedures to generate UAS-mRFP-synapsin and UAS-eGFP-synapsin constructs with $\mathrm{N}$-terminal fusion tags. Microinjection of constructs was performed by Genetics Services. For fluorescence recovery after photobleaching (FRAP) and rescue experiments, the Syn-eGFP and Syn-mRFP lines were brought into the synapsin-null $[\operatorname{Syn}(-)]$ background to generate elav-Gal4;UAS-CD8GFP;Syn (-). The line elav-Gal4;UAS-CD8GFP; UAS-Syn-mRFP was generated for simultaneously monitoring synaptic growth and synapsin movement. Canton-S (Bloomington Stock Center) was used as control. The GFP-tagged synaptotagmin line (Syt-eGFP; Zhang et al., 2002) and the UAS-GFP line were obtained from the Bloomington Stock Center.

Live imaging. Third instar larvae were dissected in low-Ca ${ }^{2+}$ hemolymph-like (HL) 3.1 saline (in mM: $70 \mathrm{NaCl}, 5 \mathrm{KCl}, 20 \mathrm{MgCl}_{2}, 0.2$ $\mathrm{CaCl}_{2}, 10 \mathrm{NaHCO}_{3}, 5$ trehalose, 115 sucrose, 2.5 HEPES- $\mathrm{HCl}, 2.5$ HEPES- $\mathrm{NaOH}$, pH 7.27.4) at room temperature. Motor nerves were carefully cut below the ventral nerve cord, and the CNS was removed. The preparation was washed several times with the same low- $\mathrm{Ca}^{2+}$ HL 3.1 saline and allowed to rest for $5 \mathrm{~min}$. Muscles 6/7 from abdominal segments 2-4 were imaged using a real-time laser-based confocal unit (PerkinElmer Life Sci) equipped with a CCD camera (Hamamatsu ORCA ER) using a $60 \times / 1$ numerical aperture waterimmersion objective (Zeiss). $Z$ stacks were taken at a $1 \mu \mathrm{m}$ step to image the entire NMJ. The preparations were stimulated with high- $\mathrm{K}^{+}$saline (in $\mathrm{mm}: 40 \mathrm{NaCl}, 90 \mathrm{KCl}, 20$ $\mathrm{MgCl}_{2}, 1.5 \mathrm{CaCl}_{2}, 10 \mathrm{NaHCO}_{3}, 5$ trehalose, 115 sucrose, 2.5 HEPES- $\mathrm{HCl}$, 2.5 HEPES-NaOH, $\mathrm{pH}$ 7.2-7.4). Alternatively, the axon was stimulated via a suction electrode using suprathreshold depolarization at a frequency of $30 \mathrm{~Hz}$. N-(3-trimethylammoniumpropyl)-4-(6-[4(diethylamino)phenyl]hexatrienyl pyridinium dibromide (FM 5-95; Invitrogen; $10 \mu \mathrm{M}$ ) was loaded during $5 \mathrm{~min}$ application of the high- $\mathrm{K}^{+}$ 
solution. The dye was washed for $5 \mathrm{~min}$ in $\mathrm{Ca}^{2+}$-free solution (in mM: $70 \mathrm{NaCl}, 5 \mathrm{KCl}, 20$ $\mathrm{MgCl}_{2}, 0 \mathrm{CaCl}_{2}, 10 \mathrm{NaHCO}_{3}, 5$ trehalose, 115 sucrose, 2.5 HEPES-HCl, 2.5 HEPES-NaOH, $\mathrm{pH}$ 7.2-7.4). Destaining was performed during 7 min high- $\mathrm{K}^{+}$solution application with no dye added. All images were analyzed using Volocity software (Improvision). For quantitative fluorescence measurements, we calculated the fluorescence above background, as described by Akbergenova and Bykhovskaia (2007). The same area and background values were used for the preparations before and after the stimulation, and all images were contrasted with identical settings.

Immunohistochemistry. Larvae were fixed for $45 \mathrm{~min}$ in HL 3.1 saline containing $4 \%$ formaldehyde. Following washing in PBST $(0.1 \%$ Triton X-100 containing $1 \times$ PBS solution), larvae were preincubated in the blocking solution containing $2 \%$ normal goat serum, $2 \%$ bovine serum albumin, and $0.05 \%$ sodium azide for $1 \mathrm{~h}$. Primary antibody was applied overnight at $4^{\circ} \mathrm{C}$. The secondary antibody was applied for 4-6 h at room temperature. Antibodies were diluted as follows: mouse NC82 [anti-bruchpilot (anti-Brp), 1:100; Developmental Studies Hybridoma Bank (DSHB)]; mouse DLG (Discs large; anti-DLG, 1:100; DSHB); horseradish peroxidase (HRP) conjugated to Alexa488 and Texas red (anti-HRP, 1:200; Jackson Immuno Research); Texas red-conjugated goat anti-mouse (1:200; Santa Cruz Biotechnology). Confocal imaging of fixed tissue was performed using an oil immersion $50 \times / 0.9$ objective (Olympus).

$E M$. Preparations were fixed in the $2.5 \%$ glutaraldehyde, $4 \%$ paraformaldehyde in $90 \mathrm{~mm}$ sodium cacodylate buffer with $0.02 \mathrm{mM} \mathrm{CaCl}_{2}$ added and $\mathrm{pH}$ adjusted to 7.2-7.4. The preparations were kept in the fixative in the microwave at $40^{\circ} \mathrm{C}$ for $2 \mathrm{~min}$ and then at room temperature for $15 \mathrm{~min}$ (protocol adapted from Akbergenova and Bykhovskaia, 2010). After brief washing with $90 \mathrm{~mm}$ sodium cacodylate buffer, preparations were postfixed in $1 \%$ osmium tetroxide $\mathrm{OsO}_{4}$ with $1.5 \% \mathrm{KFeCN}$ for $30 \mathrm{~min}$, washed in distilled water, incubated in $1 \% \mathrm{OsO}_{4}$ for $30 \mathrm{~min}$, and then incubated in a $2 \%$ aqueous solution of uranyl acetate $\mathrm{UO}_{2}\left(\mathrm{CH}_{3} \mathrm{OCO}\right)_{2} \cdot 2 \mathrm{H}_{2} \mathrm{O}$ for $1 \mathrm{~h}$ and washed. The preparations were then dehydrated through a graded series of acetone and embedded in a 1:1 mixture of EMBed-812 and SPURR (Electron Microscopy Sciences). Ultrathin sections (50-60 nm) were cut with a Leica Ultracut ultramicrotome mounted on copper slot Formvar-coated grids and examined with a JEM 100C transmission electron microscope (JEOL).

\section{Results}

Structural analysis of newly formed synaptic boutons reveals early stages of synapse development

Using a modified synaptic growth assay that employs a spaced stimulation protocol (Fig. 1A; modified from Ataman et al., 2008), we followed synaptic growth (Fig. 1B) using transgenic lines expressing a fluorescently tagged neuronal membrane protein (CD8-GFP). The stimulation was performed either by high- $\mathrm{K}^{+}$application (90 $\mathrm{mm}$ for $2 \mathrm{~min}$ ) or by high-frequency electrical stimulation of the nerve $(30 \mathrm{~Hz}$ for $5 \mathrm{~min})$. Both protocols robustly induced budding of new presynaptic boutons within $30 \mathrm{~min}$, providing an easily quantifiable assay for rapid
C
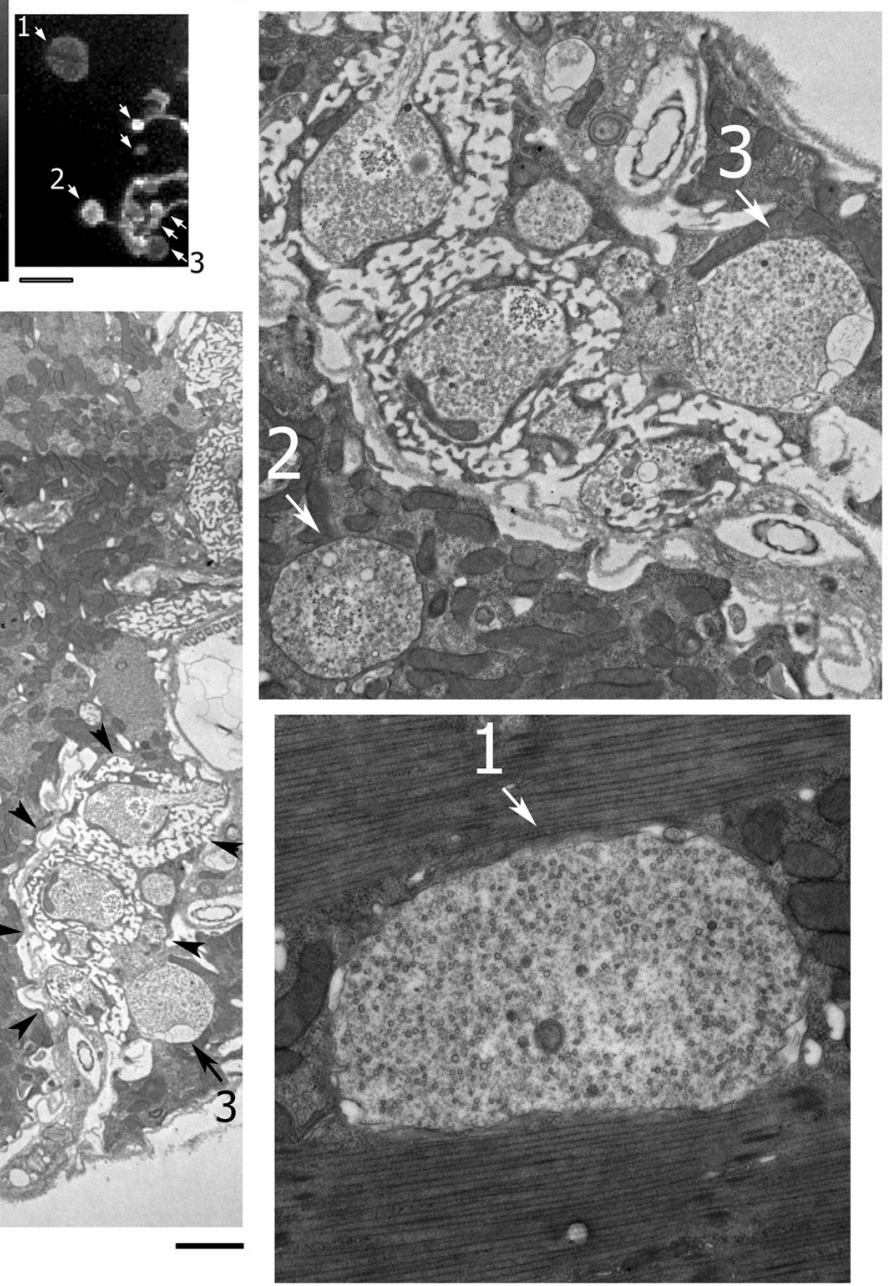

Figure 2. Correlative light/EM analysis and identification of new boutons on electron micrographs. $\boldsymbol{A}$, Confocal image of a Electron micrograph showing a section from the boxed region shown in $\boldsymbol{A}$. This plane shows three new boutons $(1,2,3)$ formed around a cluster of synaptic boutons surrounded by the SSR (arrowheads). Scale bar, $2 \mu \mathrm{m}$. C, Close-ups of boutons 2 and 3 at the edge of the synaptic cluster (top), as well as bouton 1 (bottom).

activity-induced synaptic remodeling (Fig. 1C). Importantly, all the experiments were performed using NMJs where the axon was severed from the cell body, demonstrating that the mechanisms underlying budding and outgrowth are local to the nerve terminal. Double immunolabeling of stimulated preparations with presynaptic (anti-HRP) and postsynaptic (anti-DLG) markers demonstrated that new boutons are typically formed at the edge of postsynaptic specializations, and are not usually surrounded by postsynaptic DLG (Fig. 1D). These newly formed boutons have been previously termed "ghost boutons" due to their lack of postsynaptic maturation at this stage of development.

Labeling for the active zone (AZ) marker BRP (Wagh et al., 2006) with the NC82 monocloclonal antibody (which specifically labels synaptic AZs in Drosophila) demonstrated that the majority of new boutons do not possess AZs, although some NC82 labeling was detected in $\sim 30 \%$ of new boutons (Fig. $1 E, F$ ). This finding raised the possibility that a small subset of newly formed boutons may be functional and recycle synaptic vesicles. To address this question, we labeled stimulated preparations with the endocytic marker FM 5-95 (the dye was loaded during 5 min high- $\mathrm{K}^{+}$application after the outgrowth was induced with the 

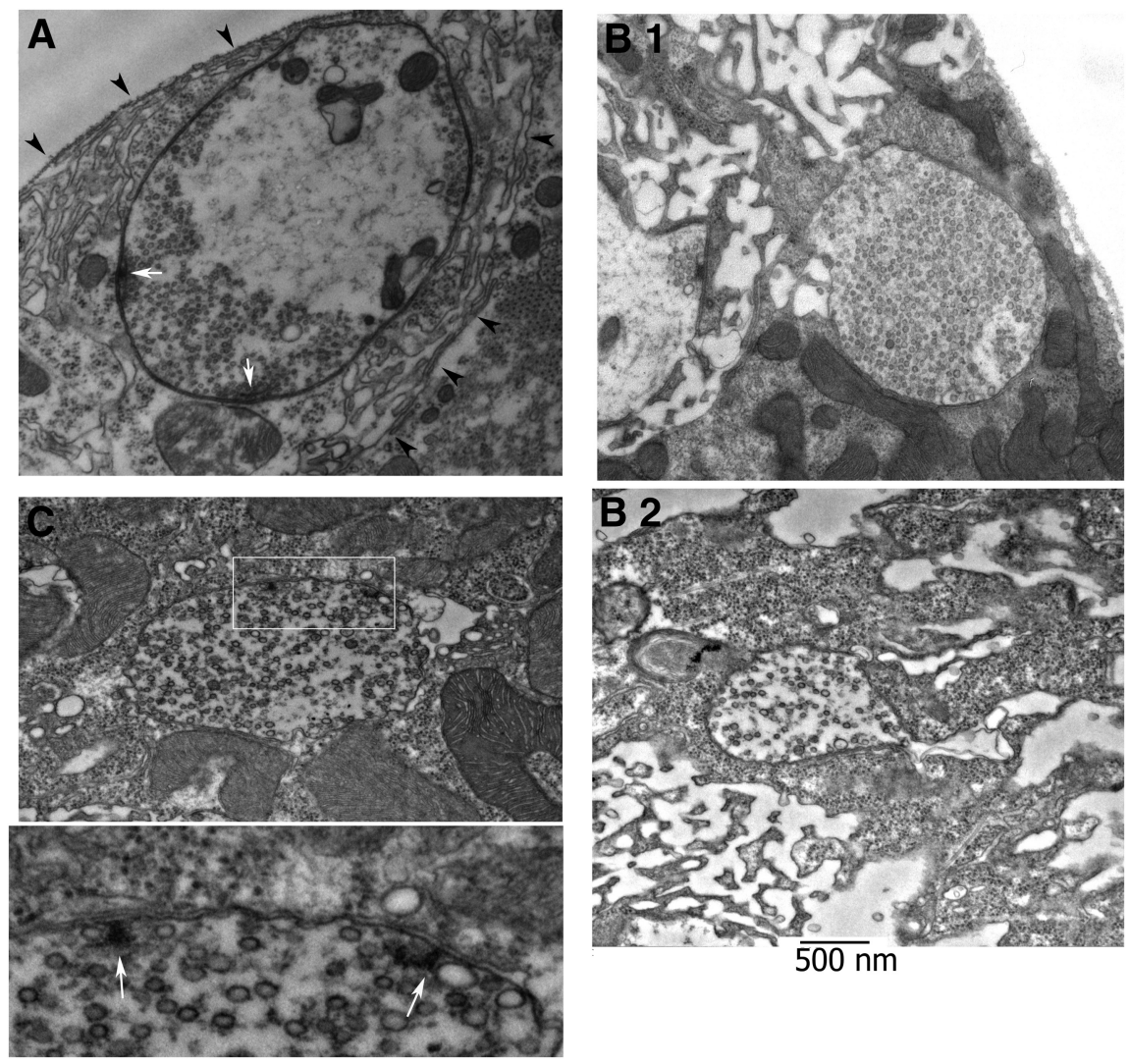

Figure 3. Ultrastructure of new boutons. $A$, Micrograph of a typical mature bouton with clustered vesicles, SSR (arrowheads), and AZs (arrows). $\boldsymbol{B}$, Images showing new boutons at in the vicinity of pre-existing clusters. Arrowheads (B.1 and B.2) show cisternae in the vicinity of the boutons in muscle tissue, which may represent a precursor of the forming SSR. C, Micrograph showing a new bouton with two AZs (T-bars) surrounded by vesicles. The boxed area is enlarged at the bottom panel. Note the absence of the SSR around the bouton, even though the T-bars (white arrows) appear to be fully formed.

protocol presented in Fig. 1A). We found that the vast majority of new boutons did not uptake the dye (Fig. 1G), including most boutons that displayed NC82 staining (Fig. $1 F$ ). Approximately $5 \%$ of all new boutons showed uptake of FM 5-95 (Fig. $1 F$ ). Importantly, however, the boutons that did uptake dye were also destained by a subsequent high- $\mathrm{K}^{+}$application, suggesting that the observed FM 5-95 staining in these new boutons is due to local vesicle recycling rather than trafficking of stained vesicles from adjacent boutons.

To further analyze presynaptic development during the early growth of new synaptic varicosities, we performed ultrastructural analysis of stimulated NMJs and identified newly formed boutons using EM. Serial sectioning was performed in parallel to the surface of the muscle and new boutons were identified by systematic comparison of confocal images and EM micrographs, as shown in Figure 2. Analysis of four stimulated preparations enabled us to identify 23 newly formed boutons and to characterize their ultrastructure. We examined the new varicosities for ultrastructural hallmarks of mature boutons observed at rest (Fig. 3A): extensive subsynaptic reticulum (SSR; arrowheads) and vesicles clustered over the periphery and at multiple AZs (white arrows). We found that new boutons were typically formed at the edge of the SSR and around clusters of pre-existing boutons (Fig. 3B). New boutons lacked SSR and postsynaptic specializations, although occasionally we observed cisternae-like structures in muscle tissue in their vicinity (Fig. $3 B$, arrowheads) that might represent precursors of forming SSR. New boutons were typically filled with vesicles that were typically spread uniformly and not clustered at the periphery as observed in mature boutons (Fig. 3B). In a small subset of newly formed varicosities, we occasionally observed T-bars surrounded by vesicles (Fig. 3C). Strikingly, although vesicles were docked in the vicinity of T-bars, they did not oppose any detectable postsynaptic specializations in the muscle, although presynaptic and postsynaptic membranes were clearly detectable and separated by $\sim 20 \mathrm{~nm}$ (Jahromi and Atwood, 1974), suggesting that a synaptic connection may be forming. Thus, differentiating presynaptic boutons, which possessed vesicles and occasionally AZs in the absence of any detectable postsynaptic structures, suggest a subset of new boutons can begin to mature during the stimulation paradigm. These results indicate that formation of presynaptic specializations precedes the formation of postsynaptic specializations during activityinduced synaptic growth at the Drosophila NMJ.

\section{Synapsin promotes budding and outgrowth of new varicosities via cAMP-dependent pathway}

To investigate presynaptic mechanisms controlling budding and outgrowth, we focused on the phosphoprotein synapsin, which has been demonstrated to play a role in both synaptic plasticity and neurodevelopment. First, we assayed synaptic growth in genetically modified Syn $(-)$ larvae. Initially, we counted the number of ghost boutons lacking postsynaptic specializations in resting and high- $\mathrm{K}^{+}$-stimulated Syn $(-)$ preparations. We found that in both cases, ghost boutons were significantly reduced in the absence of synapsin (Fig. $4 A, B$ ). This defect was rescued by reintroducing synapsin into the syn$\operatorname{apsin}(-)$ mutant background. However, synapsin overexpression did not promote further outgrowth. Next, we generated CD8-GFP transgenics in the Syn(-)- background and assayed synaptic growth directly, using the high- $\mathrm{K}^{+}$-stimulation protocol shown in Figure $1 A$. We found that activity-induced synaptic growth in Syn $(-)$ larvae was reduced by $\sim 60 \%$ (Fig. $4 C, D$ ).

Since Syn $(-)$ NMJs had reduced numbers of ghost boutons at rest, we assayed whether loss of synapsin altered NMJ structure. In agreement with Godenschwege et al. (2004), we found that the loss of synapsin did not affect the number of synaptic boutons per $\mathrm{NMJ}$ in third instar larvae at rest [71.81 $\pm 3.08, n=16$ in Syn $(-)$ vs $71.56 \pm 4.28, n=16$ in $\operatorname{Syn}(+)$ at muscles $6 / 7 ; 24.96 \pm 1.86$, $n=27$ in $\operatorname{Syn}(-)$ vs $22.73 \pm 1.79, n=22$ in $\operatorname{Syn}(+)$ at muscle 4]. These findings indicate that synapsin function is primarily required for newly generated boutons induced by strong activity, suggesting an important role for the protein in translating neuronal activity to the formation of new vesicle clusters and the budding of new varicosities.

If this is the case, we might expect that synapsin(-)mutant would not only bud fewer boutons in response to strong activity, but that the new boutons that do form would contain fewer synaptic vesicles. To test this prediction, we investigated newly formed boutons in Syn (-) NMJs. To assay vesicle content in 
newly formed boutons, we performed immunolabeling for the vesicle-associated proteins Synaptotagmin (Syt) and Cysteine String Protein (CSP) in Syn $(+)$ and $\operatorname{Syn}(-)$ boutons. We found that both Syt and CSP fluorescence was significantly reduced in newly formed $\operatorname{Syn}(-)$ boutons (Fig. 5A-H). Furthermore, Syn (-) NMJs had a significant proportion of new boutons that did not show any Syt or CSP labeling (Fig. 5G). In contrast, such boutons were rare in $\operatorname{Syn}(+)$ NMJs. In addition, HRP labeling revealed that new boutons in $\operatorname{Syn}(-)$ preparations are significantly smaller than those in $\operatorname{Syn}(+)$ preparations (Fig. $5 F$ ). Since it was shown earlier that $\operatorname{Syn}(-)$ terminals have significantly reduced vesicle content ( $\mathrm{Li}$ et al., 1995; Rosahl et al., 1995; Gitler et al., 2004; Samigullin et al., 2004), and that this phenomenon is conserved between vertebrates and invertebrates (Hilfiker et al., 1999; Humeau et al., 2011), we also used immunolabeling to assess vesicle content in mature Syn(minus]) boutons. We found that although CSP and Syt levels are reduced in mature $\operatorname{Syn}(-)$ boutons (Fig. $5 H$ ), as might be expected from EM analysis (Akbergenova and Bykhovskaia, 2010), Syt depletion is not as severe as in newly formed Syn (-) boutons (Fig. 5E). Thus, synaptic vesicle depletion in $\operatorname{Syn}(-)$ synapses may be the result of their impaired growth and development.

Since synapsin is a PKA target in vertebrates and invertebrates, and since the cAMP/PKA pathway has been shown to contribute to neuronal development in many organisms, including Drosophila (Kim and $\mathrm{Wu}, 1996$; Ueda and $\mathrm{Wu}, 2012$ ), we tested whether raising cAMP levels would promote activity-dependent synaptic outgrowth. NMJ preparations were pretreated with forskolin $(10 \mu \mathrm{M})$ for $1 \mathrm{~h}$, and then a high- $\mathrm{K}^{+}$patterned stimulation (Fig. 1A) was used. We found that forskolin pretreatment significantly promoted activity-dependent synaptic growth (Fig. 6), and that this effect was completely abolished in $\operatorname{Syn}(-)$ preparations. These data suggest that raising cAMP levels may promote phosphorylation of synapsin, which in turn enhances activity-dependent synaptic growth.

\section{Upon stimulation, synapsin redistributes toward the sites of bouton outgrowth}

Since synapsin was shown to dissociate from vesicles and disperse from synaptic boutons during activity in hippocampal cultures (Chi et al., 2001), we hypothesized that synapsin redistribution followed by vesicle reclustering may contribute to activity-induced budding of new boutons. To examine these mechanisms, we investigated the dynamics of synapsin trafficking during the growth process. To assay synapsin localization dynamically during synapse stimulation, we generated transgenic animals expressing eGFP-tagged synapsin (Syn-eGFP) and used FRAP to investigate synapsin trafficking between boutons at rest and during stimulation. We

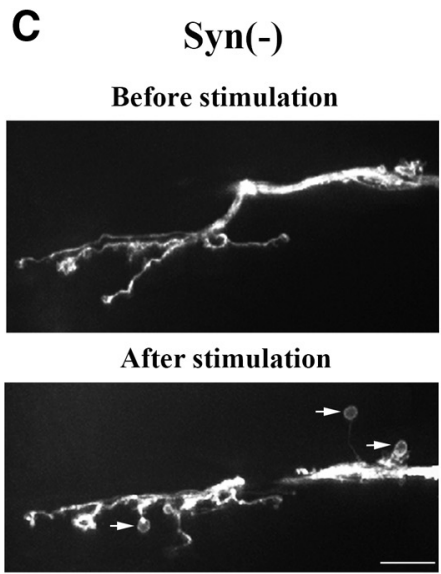

D

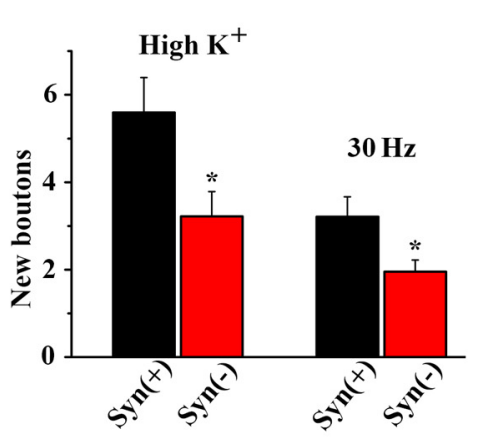

Figure 4. Neuronal outgrowth is inhibited in the absence of synapsin. $\boldsymbol{A}$, HRP/DLG immunolabeling of stimulated preparations shows ghost boutons (arrows) with no DLG labeling. $\boldsymbol{B}$, Stimulation promotes the growth of ghost boutons over-expression $(0 \mathrm{E})$, respectively] in unstimulated preparations and $43,35,28$, and 32 segments in stimulated preparations ( $>6$ larvae per line per condition). C, Assessing activity-dependent formation of new boutons in Syn( - ) preparations with GFP-tagged neuronal membranes using live confocal imaging. $\boldsymbol{D}$, Activity-dependent formation of new boutons the number of new boutons formed either upon high $-\mathrm{K}^{+}$patterned application (high $\mathrm{K}^{+}$) or upon electrical stimulation of the nerve $(30 \mathrm{~Hz})$. Data collected from $42 \mathrm{Syn}(+)$ and $28 \mathrm{Syn}(-)$ segments with high- $\mathrm{K}^{+}$stimulation, and 54 Syn $(+)$ and $22 \operatorname{Syn}(-)$ segments with electrical stimulation ( $\geq 6$ larvae per line per condition).

found that fluorescence recovery was significantly enhanced when preparations were stimulated after photobleaching (Fig. $7 A$ ). Interestingly, this was not the case for terminally positioned boutons (Fig. $7 B$ ), which showed no recovery either in the absence or presence of stimulation. This result suggests that synapsin may be redistributed locally between adjacent boutons, and that synapsin movement to terminal points of this trafficking pathway is compromised. To test whether synapsin is redistributed from adjacent boutons or trafficked over the entire NMJ, we repeated the above experiment while bleaching a bouton of interest and two adjacent boutons (Fig. 7C). We found that in the absence of stimulation, Syn-eGFP fluorescence did not recover at the centrally positioned bouton within $1 \mathrm{~h}$. However, stimulation significantly enhanced recovery, suggesting that neuronal activity intensifies synapsin trafficking between neighboring boutons and also promotes long-distance trafficking of the protein across boutons. We next examined whether synapsin is trafficked in the vesicle-associated form, or dissociates from vesicles upon stimulation and then redistributes between boutons. To address this question, we assayed transgenic lines expressing GFP-tagged Syt (Zhang et al., 2002). Since Syt is a transmembrane synaptic vesicle protein, its FRAP dynamics should reflect vesicle movement. We 
A

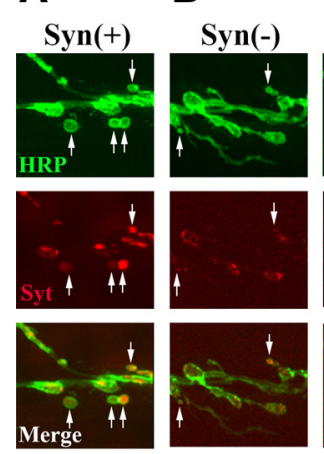

C
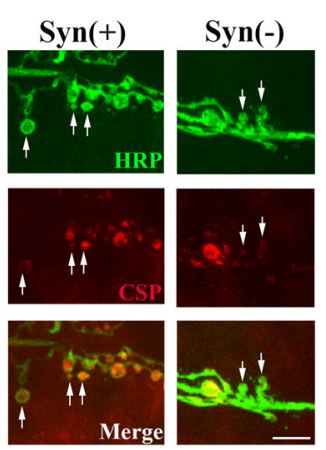

E Syt CSP
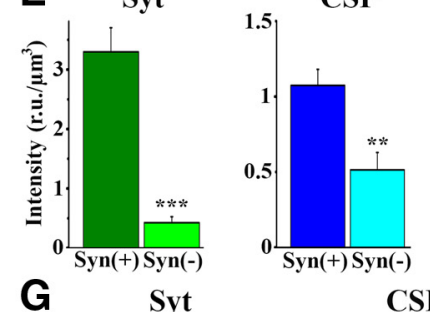

$\mathbf{F}$
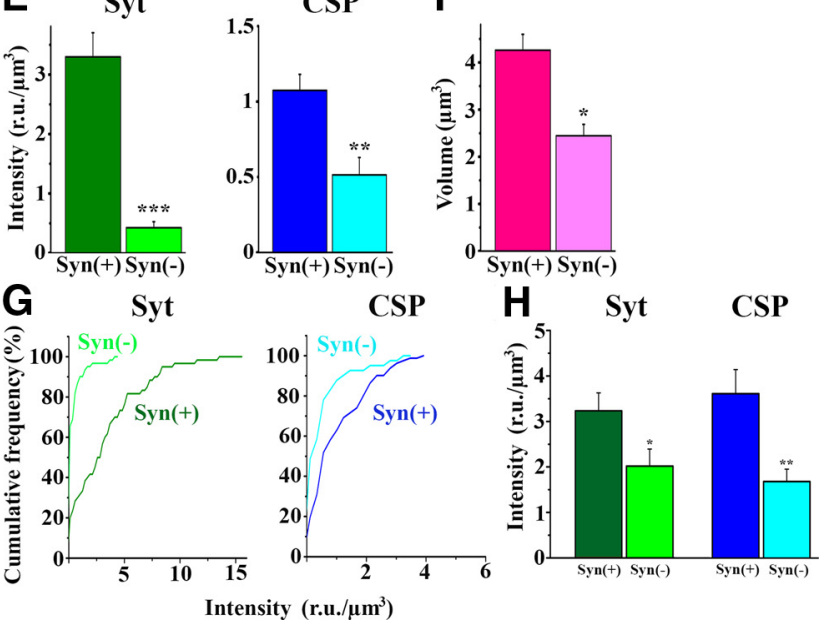

Figure 5. In Syn (-) preparations, newly formed boutons have reduced content of Syt and CSP, as well as reduced size. $\boldsymbol{A}, \boldsymbol{B}, \mathrm{HRP} / \mathrm{Syt}$ double labeling of stimulated preparations. New boutons (arrows) show prominent Syt fluorescence in Syn $(+)$ but not in Syn $(-)$ boutons. $C, D$, HRP/CSP double labeling of stimulated preparations. New boutons (arrows) show prominent CSP fluorescence in Syn(+) but not in Syn(-) boutons. $E$, Mean Syt and (SP fluorescence intensity in new boutons is significantly reduced in Syn (-) NMJs (Syt: $p<0.001$; CSP: $p<$ 0.001 per unpaired 2 -sided $t$ test). Data collected from seven larvae ( $\geq 50$ segments) per line. $\mathrm{RU}$, Relative units (background-subtracted fluorescence value in individual pixels averaged over the confocal stacks). $\boldsymbol{F}$, The size of new boutons is significantly reduced in Syn $(-)$ preparations $(p<0.00006, n>100)$. Data collected from 14 larvae per line. The volume of each bouton was calculated from 3D confocal stacks. G, Cumulative histograms of Syt and CSP fluorescence in the new boutons are shifted to the left in Syn (-) NMJs, showing a significant proportion of new boutons without Syt or CSP fluorescence. $\boldsymbol{H}$, Mature boutons in Syn $(-)$ NMJs have significantly reduced Syt $(p<0.04)$ and $\operatorname{CSP}(p<0.001)$ per unpaired two-sided $t$ test. Note that the decrease in Syt fluorescence is not as prominent as in new boutons. Data collected from seven larvae ( $\geq 35$ segments) per line.

found that Syt-GFP fluorescence did not recover in the absence of stimulation, and the recovery observed upon stimulation was significantly weaker than synapsin recovery (Fig. $8 A, B$ ). These results suggest that activity stimulates movement of synapsin in a vesicle-dissociated form. Finally, FRAP analysis of a line expressing cytosolic GFP alone demonstrated prominent trafficking of the cytosolic marker between boutons, with the recovery of GFP being independent of stimulation and significantly exceeding the recovery of synapsin. Interestingly, the movement of either vesicle or cytosolic marker at terminally positioned boutons did not appear different from the redistribution of the marker at more centrally positioned parts of the NMJ, although synapsin movement shows a prominent distinction at terminal boutons, where its movement is compromised (Fig. $7 A, B$ ). This pattern points to a possibility of directed synapsin transport, as opposed to passive diffusion. Together, these experiments demonstrate that stim-
Syn (+) + Forskolin
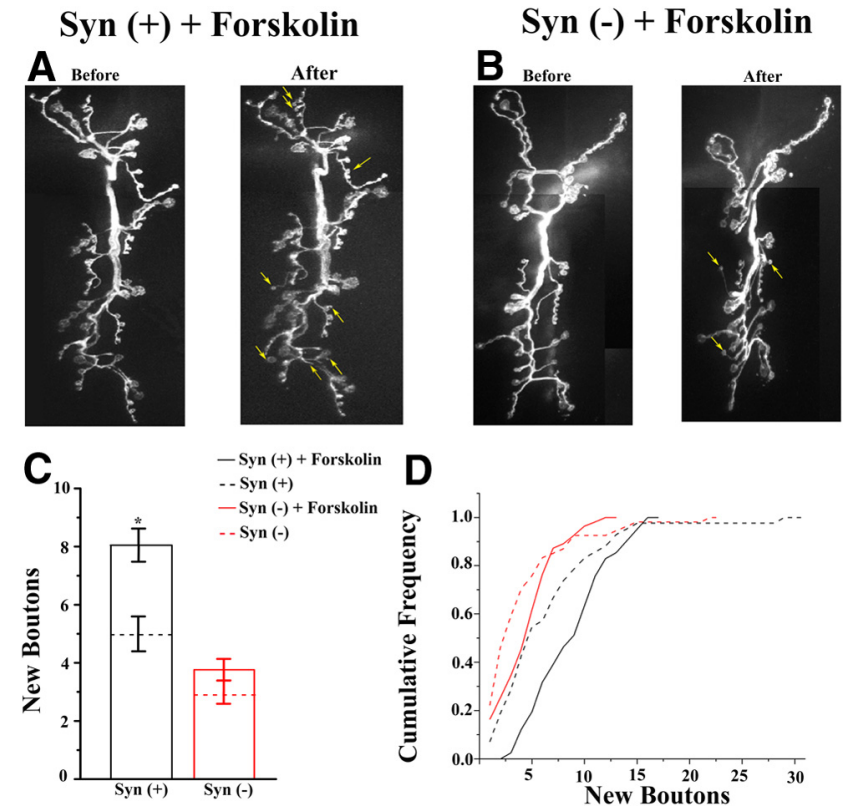

Figure 6. Forskolin pretreatment promotes activity-dependent synaptic growth in Syn $(+)$ but not in Syn $(-)$ preparations. $\boldsymbol{A}$, Prominent outgrowth in pretreated Syn $(+)$ preparations. Arrows on the right panel (stimulated) indicate new boutons. $\boldsymbol{B}$, Modest outgrowth in pretreated Syn $(-)$ preparations. C, Forskolin pretreatment induces significant $(p<0.03$ per 1-way ANOVA followed by Tukey's post hoc test) increase in synaptic growth in Syn (+) but not in Syn $(-)$ preparations. Data collected from $n=40 \operatorname{Syn}(+)$ and $n=55 \operatorname{Syn}(-)$ forskolintreated preparations ( $\geq 7$ larvae per line). Dotted lines correspond to untreated preparations (the same as in Fig. 4D, shown for comparison). D, Cumulative frequency distribution of Syn $(+$ ) pretreated preparations is shifted to the right, indicating enhanced outgrowth. The cumulative frequency distributions for Syn $(-)$ are similar for treated and untreated preparations.

ulation promotes redistribution of synapsin between boutons, and that synapsin largely redistributes in a vesicle-dissociated form.

These results suggest a model whereby synapsin may redistribute toward the sites of outgrowth during stimulation, where it may help promote the formation of new boutons. To test this hypothesis, we generated transgenic lines coexpressing CD8-GFP and Syn-mRFP to investigate how both markers are altered upon patterned depolarization. We found that, upon stimulation, synapsin fluorescence tends to accumulate in the vicinity of sites where new boutons are formed (Fig. 9A; note the increase in Syn-mRFP fluorescence at the branch where three new boutons were formed). Furthermore, new boutons typically contain prominent synapsin fluorescence (Fig. 9A, arrows), suggesting trafficking from existing boutons to newly formed varicosities. To quantify Syn-mRFP redistribution, we measured the fluorescence intensity before and after the stimulation at sites of outgrowth versus control sites with no outgrowth (Fig. 9B). The sites with single new boutons were analyzed separately from sites where multiple new boutons formed. The area where fluorescence was measured and the background threshold were kept constant, and the increase in the total fluorescence before and after stimulation was calculated. We found that sites where multiple new boutons were formed had $>100 \%$ increase in SynmRFP fluorescence, while no significant increase was observed at control sites (Fig. 9C,D). These findings indicate that synapsin moves toward the sites of new bouton growth. As such, synapsin may promote formation of vesicle clusters that would subsequently bud into new compartments, thus contributing to the formation of new synaptic boutons. 


\section{Discussion}

In the present study, we took advantage of the Drosophila NMJ to investigate stages and presynaptic mechanisms of activityinduced synapse formation. In Drosophila larvae, both glutamatergic (Ataman et al., 2008) and octopominergic (Koon et al., 2011) terminals show outgrowth in response to patterned depolarization. Previous work has suggested that some of these new structures undergo degradation via glial and muscle-mediated mechanisms, while others are likely to stabilize and develop into mature synaptic boutons (Fuentes-Medel et al., 2012). To identify stages in synaptic development, we performed EM analysis of newly formed synaptic structures following patterned stimulation with high $\mathrm{K}^{+}$. Our EM analysis revealed highly differentiated presynaptic compartments, which included synaptic vesicles and occasionally AZs in the absence of postsynaptic specializations, suggesting that development of presynaptic boutons precedes formation of postsynaptic specializations during this stimulation paradigm. To elucidate potential presynaptic mechanisms of new varicosity outgrowth, we examined the role of synapsin, which plays critical roles in synaptic vesicle clustering (for review, see Shupliakov et al., 2011), synaptic plasticity (Bykhovskaia, 2011; for review, see Fassio et al., 2011), and neurodevelopment (for review, see Valtorta et al., 2011). We found that new bouton outgrowth is severely compromised in the absence of synapsin, with fewer boutons being formed. Furthermore, new boutons that do form in the absence of synapsin are smaller and contain fewer vesicles. Finally, raising cAMP levels by forskolin pretreatment significantly promotes synaptic growth in control but not in synapsin $(-)$ preparations. Using live confocal imaging of larvae with synapsin tagged with mRFP or eGFP, we also detected movement of synapsin in response to patterned depolarization, preferentially directed to sites of outgrowth. These observations suggest a model whereby synapsin may dissociate from vesicles in response to depolarization, move toward sites of outgrowth, form new vesicle clusters, and possibly participate in actin bundling and budding of new presynaptic boutons.

\section{Stages of synapse formation and differentiation}

Growth and maturation of new synapses ultimately involves both presynaptic and postsynaptic restructuring. Although postsynaptic growth and formation of dendritic spines has been extensively studied (for review, see Holtmaat and Svoboda, 2009), the mechanisms of formation and activation of new presynaptic boutons remain obscure, even though it has been shown that structural plasticity of presynaptic terminals is associated with learning ( $\mathrm{Li}$ et al., 2011; Ruediger et al., 2011). Although tremendous progress has been achieved recently in monitoring axonal dynamics (Allegra Mascaro et al., 2013; Grillo et al., 2013), such studies in the
CNS do not allow for detailed investigation of the ultrastructure of growing synaptic boutons. In contrast, the Drosophila larval NMJ provides an excellent model system for such studies, since each motor neuron is easily identifiable, and presynaptic boutons can be visualized by using genetically encoded markers (for review, see Collins and DiAntonio, 2007). We took advantage of this preparation and used correlative light and EM to investigate the ultrastructure of newly formed boutons during activityinduced synapse formation.

This analysis enabled us to identify several ultrastructural characteristics of newly formed boutons and to make implications regarding the stages of their development. It has been previously shown (Ataman et al., 2006) that Drosophila mutants with alterations in Wingless signaling have abnormal synaptic structures with boutons lacking postsynaptic specializations and AZs: ghost boutons. A subsequent study (Ataman et al., 2008) showed that new boutons form in response to patterned depolarization at the preparations with intact axons, and that these new boutons lack postsynaptic markers (DLG), as well as the markers of AZs (BRP). The latter study also indicated that the formation of the new boutons involves the Wnt/Wg pathway and depends on 


\section{A SytGFP}
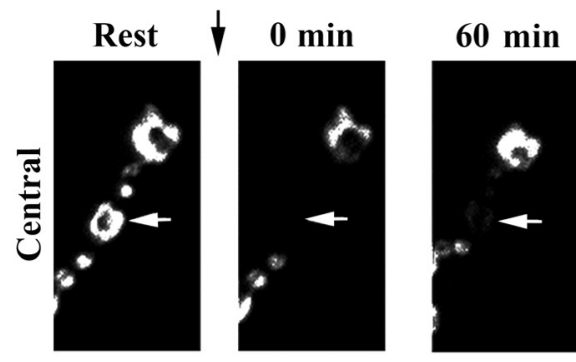

B
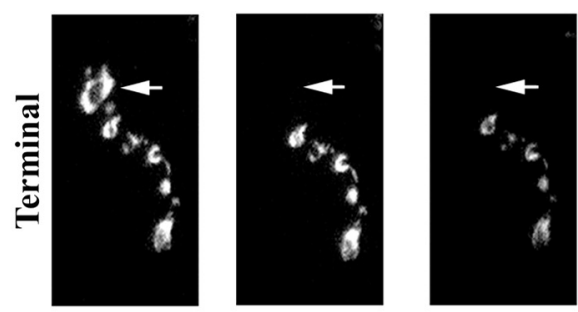

\section{CytosolicGFP}
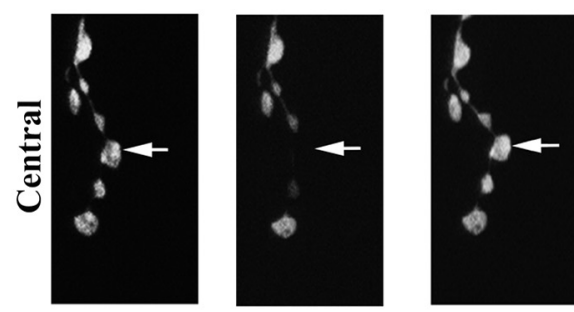

D
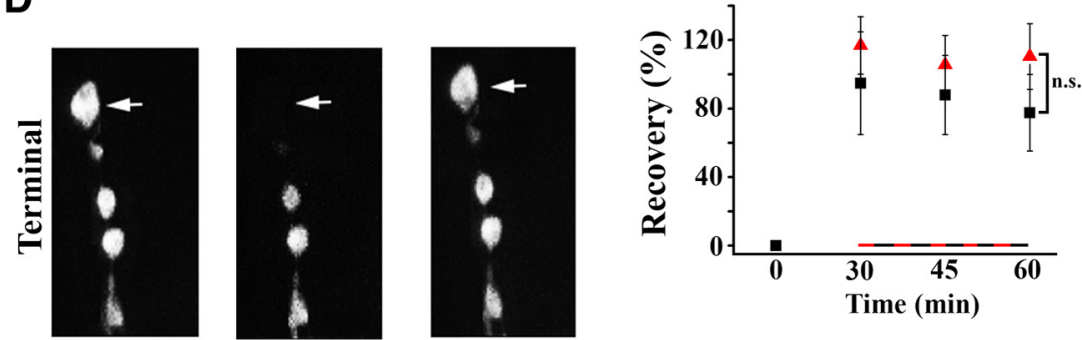

Figure 8. The movement of vesicle and cytosolic markers is not enhanced upon stimulation. $A, B$, Syt-GFP fluorescence shows no significant recovery either in the absence or in the presence of stimulation ( $n=5$ nonstimulated, $n=6$ stimulated central boutons; $n=5$ nonstimulated, $n=8$ stimulated terminal boutons). (entral and terminal boutons show a similar recovery pattern. Dotted lines show Syn-GFP fluorescence (the same as in Fig. 7, shown for comparison). C, D, Cytosolic GFP shows a significant recovery either in the absence or in the presence of stimulation. In both cases, it exceeds the recovery of Syn-GFP fluorescence (dotted lines). Central and terminal boutons show a similar recovery pattern (central, $n=7$ per condition; terminal, $n=8$ per condition).

transcription and translation. We used a shorter depolarization protocol at the larval NMJ preparation with innervating axons severed from the motor neuron cell body. We found that even though the formation of new boutons is less prominent, new boutons can still be formed within 30 min with the axon cut, indicating a component of synapse formation that is local to nerve terminals. Furthermore, a small subset of newly formed boutons possesses the AZ marker BRP and can recycle synaptic vesicles, indicating this protocol is likely to induce a program whereby some boutons begin the process of maturation to functional connections.

Our EM analysis revealed that although new boutons typically lack AZs, occasionally they included T-bars surrounded by vesicles. New boutons were filled with vesicles, but the vesicles usually lacked the organization typical for mature boutons. Membranous structures in the vicinity of the extrasynaptic space indicated the possibility that SSR formation is beginning, although a mature SSR structure was never observed around new boutons. Thus, we found that the new presynaptic specializations, including compartments with vesicles, AZs, and vesicle recycling capabilities, can be formed very rapidly and in the absence of the protein synthesis. We next examined the presynaptic mechanisms that can mediate this rapid formation of new presynaptic specializations.

\section{The role of synapsin in budding of} new boutons

In addressing this question, we focused on synapsin, which has been shown to regulate synaptic development and plasticity (for review, see Valtorta et al., 2011; Bykhovskaia, 2011). Synapsin is the most abundant presynaptic phosphoprotein that reversibly associates with synaptic vesicles, and it is a target for multiple protein kinases, including PKA (Czernik et al., 1987). Synapsins have been shown to cluster synaptic vesicles ( $\mathrm{Li}$ et al., 1995; Hilfiker et al., 1999; Siksou et al., 2007), possibly by forming connectors via dimerization and cross-linking vesicles into a mesh-work-like organization (for review, see Shupliakov et al., 2011). Binding of dephosphosynapsin to actin promotes the formation of actin bundles (Bähler and Greengard, 1987), although actin filaments were not found inside vesicle clusters, but instead were located over the periphery of vesicle clusters (Bloom et al., 2003; Sankaranarayanan et al., 2003). Synapsin disperses in response to activity (Chi et al., 2001), and experiments at Aplysia suggest that synapsin dispersion may depend on cAMP/PKA pathway (Angers et al., 2002). Synapsin expression in neuroblastoma cells induced formation of presynaptic-like structures (Han et al., 1991), and synapsin expression in nonneuronal cells gave rise to reorganization of actin filaments (Han and Greengard, 1994). Increased levels of synapsin were also shown to promote neuronal development, as well as synaptic maturation and differentiation (for review, see Valtorta et al., 2011), while synapsin deficiency slows neuronal differentiation (Ferreira et al., 1994, 1998) and synapse formation (Ferreira et al., 1995). Expression of synapsin mutants mimicking phosphorylation at the PKA site promote neurite outgrowth (Kao et al., 2002) and synapse formation (Perlini et al., 2011). However, it is still obscure how synapsin function promotes the formation of new synapses.

We took advantage of imaging capabilities at the Drosophila larval NMJ to investigate how new synaptic boutons are formed in 
A

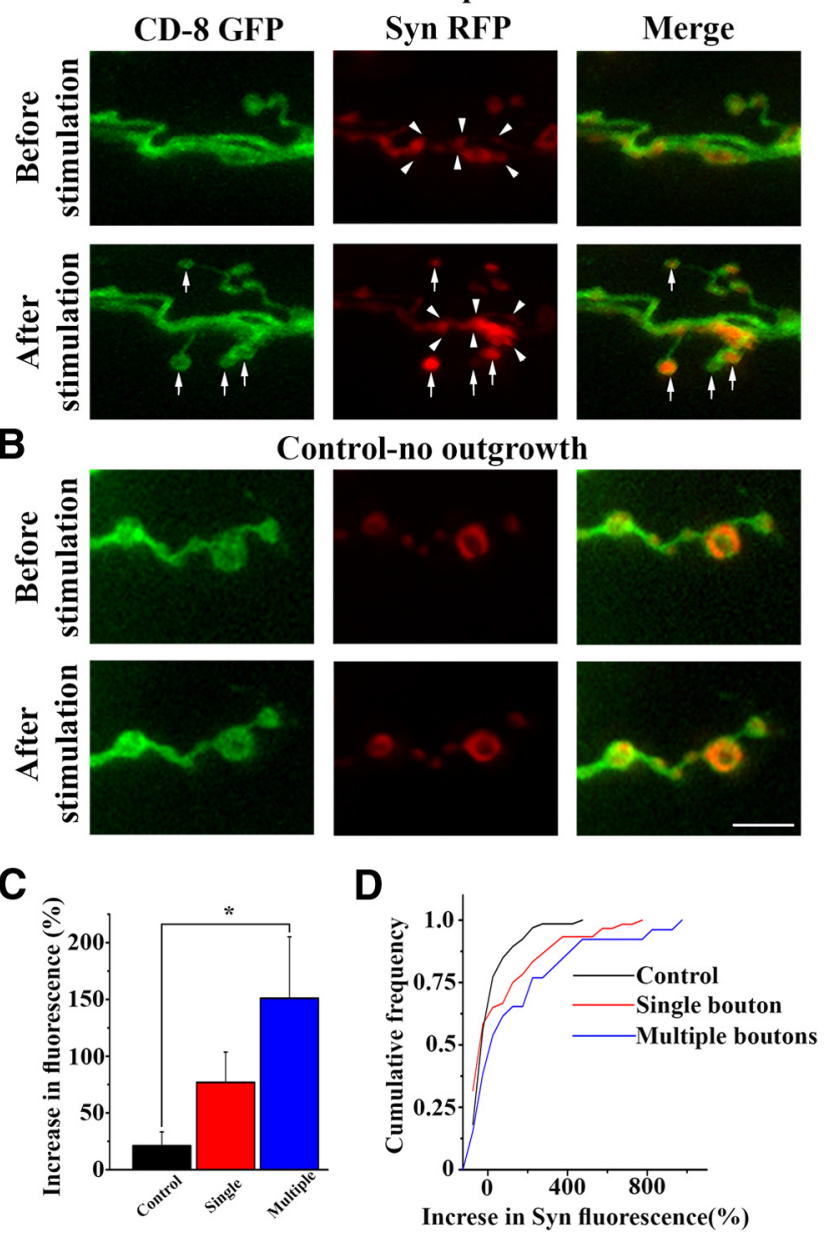

Figure 9. Synapsin redistributes toward the sites of bouton outgrowth. $A$, An example showing accumulation of Syn-mRFP fluorescence upon stimulation (arrowheads) in the vicinity of newly formed boutons (arrows). $\boldsymbol{B}$, An example showing that Syn-mRFP fluorescence does not increase at the sites where growth does not occur. $\boldsymbol{C}$, The increase in fluorescence was significant ( $p<0.05$ per 1 -way ANOVA) at sites where boutons were formed. The sites where multiple boutons were formed show a stronger increase ( $p<0.004$ per Tukey's post hoc test). Data collected from seven larvae (control, $n=66$; single, $n=60$; multiple, $n=26$ ). $D$, Cumulative frequency distributions of the increase in fluorescence. The distributions of the Syn-mRFP fluorescence increase are shifted to the right for the sites where a single bouton was formed, and the curve is shifted even farther to the right for the sites where multiple boutons were formed. Both datasets (single and multiple boutons) are significantly different from control per Kolmogorov-Smirnov test ( $p<0.05$ for single boutons; $p<0.01$ for multiple boutons).

the absence of synapsin and also to investigate activity-dependent synapsin movement. In Drosophila, synapsin is encoded by a single gene (Klagges et al., 1996), and synapsin knock-out flies are viable, although they show impaired behavior (Godenschwege et al., 2004) and altered vesicle cycling (Akbergenova and Bykhovskaia, $2007,2010)$. We investigated the activity-dependent formation of synaptic boutons in Syn $(-)$ larvae and found that it is compromised in several ways. First, the number of new boutons formed in response to stimulation in $\operatorname{Syn}(-)$ larvae was significantly reduced. Second, newly formed boutons that did emerge were smaller in Syn (-) larvae. Third, in the absence of synapsin, the content of vesicle proteins CSP and Syt was reduced in newly formed boutons. Finally, raising cAMP levels with forskolin pretreatment failed to promote activity-dependent outgrowth in Syn (-) larvae, although it significantly promoted synaptic growth in controls. These results suggest that synapsin is critical for activity-dependent formation of new boutons, that its role in synapse formation is likely to be mediated via cAMP-dependent phosphorylation, and that it may involve clustering of synaptic vesicles and their delivery into newly formed synaptic compartments.

In addition to these defects in activity-dependent synaptic growth in the absence of synapsin, we found that activity promotes synapsin movement toward the sites of synaptic outgrowth in control animals. Earlier studies (Chi et al., 2001) have shown that activity promotes dissociation of synapsin from vesicles and dispersion from boutons toward the axons. Similarly, our FRAP experiments show that activity stimulates synapsin movement, and that it is likely to occur in a vesicle-dissociated form. In addition, live confocal imaging experiments using CD8-GFP and Syn-mRFP double labeling demonstrate that synapsin movement is directed toward the sites of outgrowth. Together, these findings suggest that synapsin moves toward the sites of synaptic outgrowth during stimulation and promotes formation of new boutons. Although it remains to be elucidated how synapsin drives new bouton formation, we hypothesize that the protein participates in forming new synaptic vesicle clusters at budding sites, and may enhance actin reorganization to stimulate budding and recruitment of new synaptic vesicle clusters into newly forming presynaptic varicosities.

\section{References}

Akbergenova Y, Bykhovskaia M (2007) Synapsin maintains the reserve vesicle pool and spatial segregation of the recycling pool in Drosophila presynaptic boutons. Brain Res 1178:52-64. CrossRef Medline

Akbergenova Y, Bykhovskaia M (2010) Synapsin regulates vesicle organization and activity-dependent recycling at Drosophila motor boutons. Neuroscience 170:441-452. CrossRef Medline

Allegra Mascaro AL, Cesare P, Sacconi L, Grasselli G, Mandolesi G, Maco B, Knott GW, Huang L, De Paola V, Strata P, Pavone FS (2013) In vivo single branch axotomy induces GAP-43-dependent sprouting and synaptic remodeling in cerebellar cortex. Proc Natl Acad Sci U S A 110:1082410829. CrossRef Medline

Angers A, Fioravante D, Chin J, Cleary LJ, Bean AJ, Byrne JH (2002) Serotonin stimulates phosphorylation of Aplysia synapsin and alters its subcellular distribution in sensory neurons. J Neurosci 22:5412-5422. Medline

Ataman B, Ashley J, Gorczyca D, Gorczyca M, Mathew D, Wichmann C, Sigrist SJ, Budnik V (2006) Nuclear trafficking of Drosophila Frizzled-2 during synapse development requires the PDZ protein dGRIP. Proc Natl Acad Sci U S A 103:7841-7846. CrossRef Medline

Ataman B, Ashley J, Gorczyca M, Ramachandran P, Fouquet W, Sigrist SJ, Budnik V (2008) Rapid activity-dependent modifications in synaptic structure and function require bidirectional Wnt signaling. Neuron 57: 705-718. CrossRef Medline

Bähler M, Greengard P (1987) Synapsin I bundles F-actin in a phosphorylation-dependent manner. Nature 326:704-707. CrossRef Medline

Bloom O, Evergren E, Tomilin N, Kjaerulff O, Löw P, Brodin L, Pieribone VA, Greengard P, Shupliakov O (2003) Colocalization of synapsin and actin during synaptic vesicle recycling. J Cell Biol 161:737-747. CrossRef Medline

Bykhovskaia M (2011) Synapsin regulation of vesicle organization and functional pools. Semin Cell Dev Biol 22:387-392. CrossRef Medline

Chi P, Greengard P, Ryan TA (2001) Synapsin dispersion and reclustering during synaptic activity. Nat Neurosci 4:1187-1193. CrossRef Medline

Collins CA, DiAntonio A (2007) Synaptic development: insights from Drosophila. Curr Opin Neurobiol 17:35-42. CrossRef Medline

Czernik AJ, Pang DT, Greengard P (1987) Amino acid sequences surrounding the cAMP-dependent and calcium/calmodulin-dependent phosphorylation sites in rat and bovine synapsin I. Proc Natl Acad Sci U S A 84: 7518-7522. CrossRef Medline

Fassio A, Raimondi A, Lignani G, Benfenati F, Baldelli P (2011) Synapsins: 
from synapse to network hyperexcitability and epilepsy. Semin Cell Dev Biol 22:408-415. CrossRef Medline

Ferreira A, Kosik KS, Greengard P, Han HQ (1994) Aberrant neurites and synaptic vesicle protein deficiency in synapsin II-depleted neurons. Science 264:977-979. CrossRef Medline

Ferreira A, Han HQ, Greengard P, Kosik KS (1995) Suppression of synapsin II inhibits the formation and maintenance of synapses in hippocampal culture. Proc Natl Acad Sci U S A 92:9225-9229. CrossRef Medline

Ferreira A, Chin LS, Li L, Lanier LM, Kosik KS, Greengard P (1998) Distinct roles of synapsin I and synapsin II during neuronal development. Mol Med 4:22-28. Medline

Fornasiero EF, Bonanomi D, Benfenati F, Valtorta F (2010) The role of synapsins in neuronal development. Cell Mol Life Sci 67:1383-1396. CrossRef Medline

Fuentes-Medel Y, Ashley J, Barria R, Maloney R, Freeman M, Budnik V (2012) Integration of a retrograde signal during synapse formation by glia-secreted TGF- $\beta$ ligand. Curr Biol 22:1831-1838. CrossRef Medline

Gitler D, Takagishi Y, Feng J, Ren Y, Rodriguiz RM, Wetsel WC, Greengard P, Augustine GJ (2004) Different presynaptic roles of synapsins at excitatory and inhibitory synapses. J Neurosci 24:11368-11380. CrossRef Medline

Godenschwege TA, Reisch D, Diegelmann S, Eberle K, Funk N, Heisenberg M, Hoppe V, Hoppe J, Klagges BR, Martin JR, Nikitina EA, Putz G, Reifegerste R, Reisch N, Rister J, Schaupp M, Scholz H, Schwärzel M, Werner U, Zars TD, et al. (2004) Flies lacking all synapsins are unexpectedly healthy but are impaired in complex behaviour. Eur J Neurosci 20: 611-622. CrossRef Medline

Greengard P, Valtorta F, Czernik AJ, Benfenati F (1993) Synaptic vesicle phosphoproteins and regulation of synaptic function. Science 259:780785. CrossRef Medline

Grillo FW, Song S, Teles-Grilo Ruivo LM, Huang L, Gao G, Knott GW, Maco B, Ferretti V, Thompson D, Little GE, De Paola V (2013) Increased axonal bouton dynamics in the aging mouse cortex. Proc Natl Acad Sci U S A 110:E1514-E1523. CrossRef Medline

Han HQ, Greengard P (1994) Remodeling of cytoskeletal architecture of nonneuronal cells induced by synapsin. Proc Natl Acad Sci U S A 91: 8557-8561. CrossRef Medline

Han HQ, Nichols RA, Rubin MR, Bähler M, Greengard P (1991) Induction of formation of presynaptic terminals in neuroblastoma cells by synapsin IIb. Nature 349:697-700. CrossRef Medline

Hilfiker S, Pieribone VA, Czernik AJ, Kao HT, Augustine GJ, Greengard P (1999) Synapsins as regulators of neurotransmitter release. Philos Trans R Soc Lond B Biol Sci 354:269-279. CrossRef Medline

Holtmaat A, Svoboda K (2009) Experience-dependent structural synaptic plasticity in the mammalian brain. Nat Rev Neurosci 10:647-658. CrossRef Medline

Humeau Y, Candiani S, Ghirardi M, Poulain B, Montarolo P (2011) Functional roles of synapsin: lessons from invertebrates. Semin Cell Dev Biol 22:425-433. CrossRef Medline

Jahromi SS, Atwood HL (1974) Three-dimensional ultrastructure of the crayfish neuromuscular apparatus. J Cell Biol 63:599-613. CrossRef Medline

Kao HT, Porton B, Hilfiker S, Stefani G, Pieribone VA, DeSalle R, Greengard P (1999) Molecular evolution of the synapsin gene family. J Exp Zool 285:360-377. CrossRef Medline

Kao HT, Song HJ, Porton B, Ming GL, Hoh J, Abraham M, Czernik AJ, Pieribone VA, Poo MM, Greengard P (2002) A protein kinase A-dependent molecular switch in synapsins regulates neurite outgrowth. Nat Neurosci 5:431-437. Medline

Kim YT, Wu CF (1996) Reduced growth cone motility in cultured neurons from Drosophila memory mutants with a defective cAMP cascade. J Neurosci 16:5593-5602. Medline

Klagges BR, Heimbeck G, Godenschwege TA, Hofbauer A, Pflugfelder GO, Reifegerste R, Reisch D, Schaupp M, Buchner S, Buchner E (1996) In- vertebrate synapsins: a single gene codes for several isoforms in Drosophila. J Neurosci 16:3154-3165. Medline

Koon AC, Ashley J, Barria R, DasGupta S, Brain R, Waddell S, Alkema MJ, Budnik V (2011) Autoregulatory and paracrine control of synaptic and behavioral plasticity by octopaminergic signaling. Nat Neurosci 14:190199. CrossRef Medline

Korkut C, Ataman B, Ramachandran P, Ashley J, Barria R, Gherbesi N, Budnik V (2009) Trans-synaptic transmission of vesicular Wnt signals through Evi/Wntless. Cell 139:393-404. CrossRef Medline

Korkut C, Li Y, Koles K, Brewer C, Ashley J, Yoshihara M, Budnik V (2013) Regulation of postsynaptic retrograde signaling by presynaptic exosome release. Neuron 77:1039-1046. CrossRef Medline

Li L, Chin LS, Shupliakov O, Brodin L, Sihra TS, Hvalby O, Jensen V, Zheng D, McNamara JO, Greengard P (1995) Impairment of synaptic vesicle clustering and of synaptic transmission, and increased seizure propensity, in synapsin I-deficient mice. Proc Natl Acad Sci U S A 92:9235-9239. CrossRef Medline

Li W, Zheng Z, Keifer J (2011) Transsynaptic EphB/Ephrin-B signaling regulates growth of presynaptic boutons required for classical conditioning. J Neurosci 31:8441-8449. CrossRef Medline

Perlini LE, Botti F, Fornasiero EF, Giannandrea M, Bonanomi D, Amendola M, Naldini L, Benfenati F, Valtorta F (2011) Effects of phosphorylation and neuronal activity on the control of synapse formation by synapsin I. J Cell Sci 124:3643-3653. CrossRef Medline

Rosahl TW, Spillane D, Missler M, Herz J, Selig DK, Wolff JR, Hammer RE, Malenka RC, Südhof TC (1995) Essential functions of synapsins I and II in synaptic vesicle regulation. Nature 375:488-493. CrossRef Medline

Ruediger S, Vittori C, Bednarek E, Genoud C, Strata P, Sacchetti B, Caroni P (2011) Learning-related feedforward inhibitory connectivity growth required for memory precision. Nature 473:514-518. CrossRef Medline

Samigullin D, Bill CA, Coleman WL, Bykhovskaia M (2004) Regulation of transmitter release by synapsin II in mouse motor terminals. J Physiol 561:149-158. CrossRef Medline

Sankaranarayanan S, Atluri PP, Ryan TA (2003) Actin has a molecular scaffolding, not propulsive, role in presynaptic function. Nat Neurosci 6:127135. CrossRef Medline

Schaeffer E, Alder J, Greengard P, Poo MM (1994) Synapsin IIa accelerates functional development of neuromuscular synapses. Proc Natl Acad Sci U S A 91:3882-3886. CrossRef Medline

Shupliakov O, Haucke V, Pechstein A (2011) How synapsin I may cluster synaptic vesicles. Semin Cell Dev Biol 22:393-399. CrossRef Medline

Siksou L, Rostaing P, Lechaire JP, Boudier T, Ohtsuka T, Fejtová A, Kao HT, Greengard P, Gundelfinger ED, Triller A, Marty S (2007) Threedimensional architecture of presynaptic terminal cytomatrix. J Neurosci 27:6868-6877. CrossRef Medline

Ueda A, Wu CF (2012) Cyclic adenosine monophosphate metabolism in synaptic growth, strength, and precision: neural and behavioral phenotype-specific counterbalancing effects between dnc phosphodiesterase and rut adenylyl cyclase mutations. J Neurogenet 26:64-81. CrossRef Medline

Valtorta F, Iezzi N, Benfenati F, Lu B, Poo MM, Greengard P (1995) Accelerated structural maturation induced by synapsin I at developing neuromuscular synapses of Xenopus laevis. Eur J Neurosci 7:261-270. CrossRef Medline

Valtorta F, Pozzi D, Benfenati F, Fornasiero EF (2011) The synapsins: multitask modulators of neuronal development. Semin Cell Dev Biol 22:378386. CrossRef Medline

Wagh DA, Rasse TM, Asan E, Hofbauer A, Schwenkert I, Dürrbeck H, Buchner S, Dabauvalle MC, Schmidt M, Qin G, Wichmann C, Kittel R, Sigrist SJ, Buchner E (2006) Bruchpilot, a protein with homology to ELKS/ CAST, is required for structural integrity and function of synaptic active zones in Drosophila. Neuron 49:833-844. CrossRef Medline

Zhang YQ, Rodesch CK, Broadie K (2002) Living synaptic vesicle marker: synaptotagmin-GFP. Genesis 34:142-145. CrossRef Medline 